\title{
Microscopic thymoma and myasthenia gravis
}

\author{
F Puglisi, N Finato, L Mariuzzi, C Marchini, G Floretti, C A Beltrami
}

\begin{abstract}
A rare case of microscopically sized thymoma is described in a 56 year old man suffering from myasthenia gravis. Histological examination of the surgically removed thymus showed the presence of several epithelial thymoma-like islands. As controls, 100 thymuses obtained from consecutive necropsies were sampled: $4 \%$ of these cases showed epithelial islands. This case is further proof that "microscopic thymoma" is a true pathological entity and suggests that every thymus removed from myasthenic patients in which there is no macroscopic evidence of thymoma should be examined microscopically on serial sections.

(f Clin Pathol 1995;48:682-683)
\end{abstract}

Keywords: Microscopic thymoma, myasthenia gravis.

Udine, Italy:

Postgraduate School of Oncology

F Puglisi

Department of

Pathology

N Finato

L Mariuzzi

G Floretti

C Alberto Beltrami

Department of

Neurology

C Marchini

Correspondence to:

Dr Fabio Puglisi,

Istituto de Anatomia

Patologica,

Ospedale S Maria della

Misericordia, 3310 Udine,

Italy.

Accepted for publication

1 December 1994.

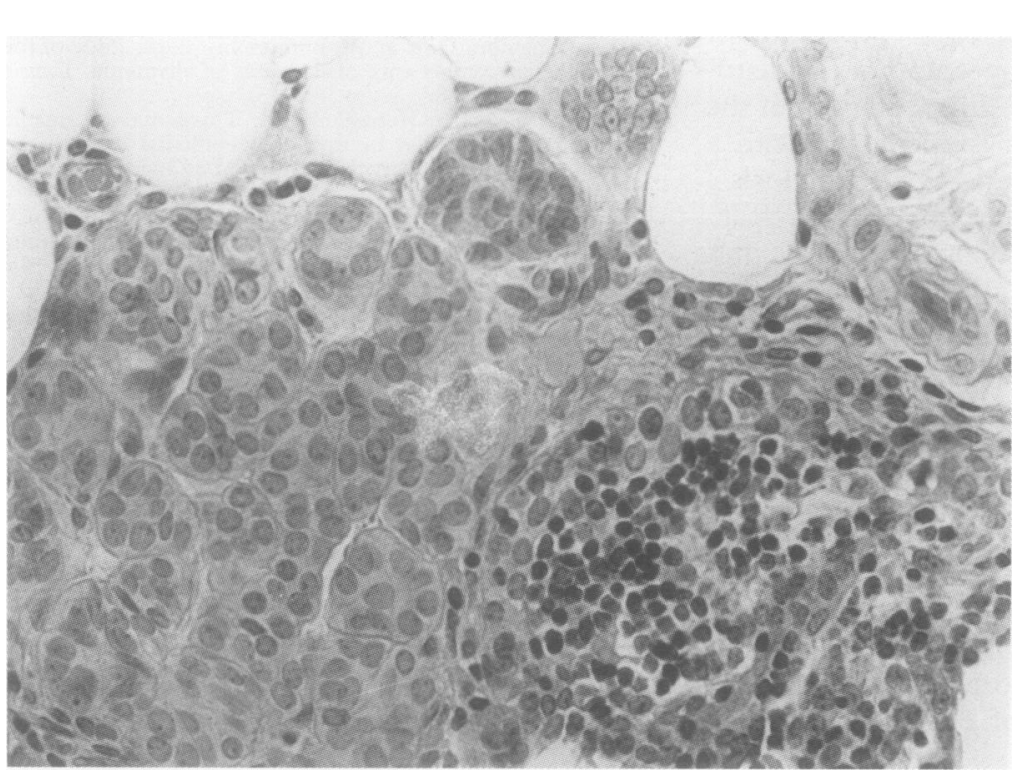

An epithelial nest histologically consistent with microscopic thymoma; it was mainly composed of oval to round cells with clear chromatin and definite nucleoli. Haematoxylin and eosin, $\times 295$ during cardiac surgery. Recently, Pescarmona et $a l^{2}$ reported three cases of microscopic thymoma in thymuses removed from patients suffering from myasthenia gravis, an autoimmune disease which often occurs in the presence of thymic abnormalities. Here we present a case of a patient suffering from myasthenia gravis whose thymus contained several foci of microscopic thymoma.

\section{Case report}

A 56 year old man with diabetes mellitus was admitted to a general hospital in September 1993 with a four year history of generalised weakness and mild fatigability of the skeletal muscles. No diagnosis was made. In December the patient was referred to the neurological department of the University of Udine because the symptoms were rapidly worsening. On examination, he had bilateral ptosis, diplopia, and easy fatigability, mostly of the muscles of the trunk and the lower limbs. A diagnosis of myasthenia gravis was made on the basis of the clinical findings, an anticholinesterase test, repetitive nerve stimulation $(40 \%$ reduction in the amplitude of the evoked muscle action potential), and positive assay for acetylcholine receptor antibodies $(0 \cdot 10 \mathrm{pmol} / \mathrm{ml})$. In view of the possibility of an associated thymic disorder, a computed tomographic scan was performed. No mediastinal enlargement was discovered. In February 1994 the patient had a surgical thymectomy by the sternum splitting approach. After thymectomy, there was progressive clinical improvement over a follow up period of seven months. Anticholinesterase agents were used as medical treatment before and after surgery.

\section{Pathological findings}

The thymus weighed $30 \mathrm{~g}$. Macroscopically it was a lobulated soft yellow gland. As controls we examined 100 thymuses obtained from consecutive necropsies to verify the presence of "thymoma-like" epithelial solid nests. The donors were 41 females, age range $<1$ to 90 years (mean $=68$ ), and 59 males, age range $<1$ to 95 years (mean $=65$ ). Thirty five samples of the myasthenic patient's thymus and 3-10 samples from each of the control thymuses were processed for conventional histology. Tissue sections were stained with haematoxylin and eosin, PAS, and Gomori for reticulum; in order to identify epithelial islands, the sections were also stained for cytokeratin with monoclonal antibody (CAM 5.2, Becton Dickinson), using the avidin-biotin peroxidase technique. The thymus of the patient with myasthenia gravis showed a variable degree of involution. Several epithelial nests of round-oval cells, with nuclear dispersed chromatin and nucleoli, were histologically detected. Mitoses and nuclear atypia were not found (figure). The observed epithelial lesions were consistent with foci of microscopic thymoma. To determine their dimensions, we measured all the immunohistochemically identified epithelial areas by an image analyser (IBAS2000, Kontron). The morphometric data showed that the largest island has an equivalent area of $272 \times 71 \mathrm{~mm}$. 
The 100 control thymuses showed several patterns of involution with a decrease in number of lymphocytes and relative preservation of the epithelial cells. In four of the 100 cases (age range 53-80 years), epithelial islands and rosette-like formations were seen. In other cases, the architectural arrangement was characterised by anastomosing strands of epithelial elements admixed with thymocytes.

The mean diameter of the epithelial nests was $107 \mathrm{~mm}$ (range $41-237 \mathrm{~mm}$ ).

\section{Discussion}

Approximately $75 \%$ of patients with myasthenia gravis have thymic abnormalities, namely lymphoid follicular hyperplasia or thymoma or both. ${ }^{34}$ Surgical thymectomy results in disease improvement in most myasthenic patients and in non-thymoma cases it is often curative, ${ }^{5}$ although the overall prognosis has not been significantly modified in large series of patients who have had thymectomy. ${ }^{67}$ The surgical approach is useful, however, in preventing spread of the thymoma. In this case we could not demonstrate the presence of a thymoma by computed tomography; nevertheless a thymectomy was performed for therapeutic purposes.

On histological examination, the islands of epithelial cells were interpreted as possible multiple foci of microscopic thymoma. This "microscopic thymoma" had a morphological pattern compatible with the descriptions of Rosai and Levine. ${ }^{1}$ Moreover, Pescarmona et al reported three other cases showing microscopic epithelial lesions $(0.2-0.4 \mathrm{~mm}$ in diameter) consistent with foci of thymoma on the basis of their morphological appearance.

Since it is also possible to find epithelial clusters in involuted thymuses, ${ }^{8}$ we analysed as controls 100 consecutive thymuses with differ- ent degrees of involution obtained at necropsy. In four of these 100 cases, epithelial islands and very small rosette-like formations were observed. These microscopic changes were similar to those present in microscopic thymoma, especially the rosette-like formations. The findings of Rosai and Levine were similar, as were those of Pescarmona et $a l^{2}{ }^{2}$ and from a morphological point of view it is quite impossible to distinguish between the two conditions. Pescarmona suggested a possible multifocal origin of thymoma. Our case supports this suggestion and underlines the association between myasthenia gravis and multifocal thymoma not associated with lymphoid follicular hyperplasia of the thymus.

In conclusion, in order to establish the unequivocal presence of a thymoma in patients suffering from myasthenia gravis it is necessary to obtain histological samples of the entire gland, particularly in those cases without macroscopically evident lesions. Finally, it is important to realise that computed tomography of the chest is unable to detect microscopic sized thymomas.

1 Rosai J, Levine GD. Tumors of the thymus. Atlas of tumor pathology, second series. Washington DC: Armed Forces pathology, second series. Was
Institute of Patholoogy, 1976.

2 Pescarmona E, Rosati S, Pisacane A, Rendina EA, Venuta F, Baroni CD. Microscopic thymoma: histopathological evidence of multifocal cortical and medullary origin. His topathology 1992;20:263-6.

3 Castleman B. The pathology of the thymus gland in myasthenia gravis. Ann N Y Acad Sci 1966;135:496-505.

4 Drachmann DB. Myasthenia gravis. N Engl f Med 1994;330: 1797-810.

5 Buckingham JM, Howard FM, Bernatz PE, Payne WS, Harrison EG, O'Brien PC, et al. The value of thymectomy in myasthenia gravis: a computer assisted matched study. Ann Surg 1976;184:453-8.

6 Evoli A, Batocchi AP, Provenzano C, Ricci E, Tonali P. Thymectomy in the treatment of myasthenia gravis: report of 247 patients. $₹$ Neurol $1988 ; 235: 272-6$.

7 Durelli L, Maggi G, Casadio C, Ferri R, Rendina S, Bergamini L. Actuarial analysis of the occurrence of remission following thymectomy for myasthenia gravis in 400 patients. F Neurol Neurosurg Psychiatry 1991;54:406-11.

8 Suster S, Rosai J. Histology of the normal thymus. Am F Surg Pathol 1990;14:284-303.

\title{
Evaluation of the API-Campy System in the biochemical identification of hippurate negative campylobacter strains isolated from faeces
}

\author{
J Reina, M J Ros, A Serra
}

Clinical Microbiology
Service, University
Hospital Son Dureta
(UIB), 07014-Palma
de Mallorca, Spain
J Reina
M J Ros
A Serra
Correspondence to:
Dr J Reina.
Accepted for publication
1 December 1994

Clinical Microbiology Service, University Hospital Son Dureta de Mallorca, Spain J Reina

M J Ros

Correspondence to:

Accepted for publicatio 1 December 1994

\author{
Abstract \\ The aim was to evaluate the efficacy of \\ the API-Campy system in the biochemical \\ identification of 62 hippurate negative \\ campylobacter strains isolated from the \\ faeces. The strains were identified man- \\ ually as 34 nalidixic acid susceptible $C$ coli \\ (NAS), 20 nalidixic acid resistant $C$ coli \\ (NAR), and eight $C$ lari. The 34 strains of
}

NAS $C$ coli were identified as such by the API-Campy system. Of the 20 strains of NAR $C$ coli, 15 (75\%) were correctly identified by the commercial system. None of the five NAR $\boldsymbol{C}$ coli strains which were also erythromycin resistant was identified as such by the system. The eight $C$ lari strains could not be identified by the API-Campy system because the bionumber obtained 
CD34 immunoperoxidase staining for the diagnosis of myelodysplastic syndromes and chronic myeloid leukaemia

Horny et $a l^{1}$ recently reported that immunoperoxidase staining of bone marrow biopsy specimens with the CD34/QBEND10 monoclonal antibody can be used to separate the myelodysplastic syndromes RAEB and RAEB-T from the RA and RARS subtypes. This report has now confirmed our previous findings that CD34/QBEND10 is a useful reagent for the study of conventionally processed, paraffin wax embedded bone marrow biopsy specimens. ${ }^{2}$ We have recently studied bone marrow biopsy specimens from 58 cases of primary myelodysplastic syndromes addressing the diagnostic value of CD34 staining in these conditions. ${ }^{3}$ We found that CD 34 immunostaining can help in the detection of the increased number of blasts associated with the RAEB and RAEB-T subtypes. In addition, our study showed that QBEND10 represents a powerful prognostic tool for predicting survival and outcome in myelodysplastic syndromes. In primary RAEB cases median survival was 41 months in those with less than $1 \%$ CD34 + cells, and 29 months in those with more than $1 \%$ CD $34+$ cells $(p<0 \cdot 05){ }^{3}$ Similar results were obtained in cases of therapy related myelodysplastic syndromes: CD34 + cases had a mean survival of 10 months compared with 43 months for the CD34 - cases $(p<0.0005){ }^{4}$

The authors also suggest the potential usefulness of CD34 staining for identifying patients in the accelerated phase of chronic myeloid leukaemia. Our recently published study of 59 bone marrow biopsy specimens representing the three phases (stable, accelerated and blastic) of chronic myeloid leukaemia has indeed confirmed the finding of a statistically higher CD34 value in the two aggressive phases of this disease compared with the stable phase. ${ }^{5}$

Taken together, these data and those from Horny et al show that QBEND10 is a very useful reagent for the study of routinely processed bone marrow biopsy specimens and may provide useful diagnostic and prognostic information in myelodysplastic syndromes and myeloproliferative disorders. This type of approach may be especially valuable when a paraffin wax embedded specimen is the only material available for immunophenotyping.

A ORAZI

Associate Professor of Pathology, Director, Section of Immunohistochemistry, Department of Pathology and Laboratory Medicine, University Hospital 4430,
Indiana University Medical Center 550 North University Blvd, SSO North University Blvd, Indianapolis Indiana 46202-5283, USA

1 Horny HP, Wehrmann M, Schlicker HUH, Eichstaedt A Clemens MR, Kaiserling E. QBEND10 for the diagnosis of myelodysplastic syndromes in routinely processed bone marrow biopsy specimens. $\mathcal{f}$ Clin Pathol 1995;48:291-4.

2 Soligo D, Delia D, Oriani A, Cattoretti G, Orazi $\mathrm{A}$, Bertolli $\mathrm{V}$, et al. Identification of CD34+ cells in normal and pathologic bone marrow biopsies by QBEND10 mo 3 Soligo D, Oriani A, Annaloro C, Cortelezzi A, Calori R, Pozzoli E, et al. CD34 immunohistochemistry of bone marrow biopsies: prognostic significance in primary myelodysplas

4 Orazi A, Cattoretti G, Soligo D, Luksch R Lambertenghi Deliliers G. Therapy-related Lambertenghi Deliliers G. Therapy-related myelodysplastic syndromes: FAB classificatistology in the prognostic assessment. Leukhistology in the prog

5 Orazi A, Neiman RS, Cualing H, Heerema N, John K. CD34 immunostaining of bone marrow biopsy specimens is a reliable way to classify the phases of chronic myeloid leu emia. Am F Clin Pathol 1994;101:426-8.

\section{Book review}

If you wish to order or require further information regarding the titles reviewed here, please write to or telephone the BMJ Bookshop, PO Box 295, London WC1H 9JR. Tel 071383 6244. Fax 071383 6662. Books are supplied post free in the UK and for British Forces Posted Overseas addresses. Overseas customers should add $15 \%$ for postage and packing. Payment can be made by cheque in sterling drawn on a UK bank or by credit card (Mastercard, Visa, or American Express) stating card number, expiry date, and full name.

(The price and availability are occasionally subject to revision by the Publishers.)

Diseases of the Bronchioles. Ed GR Epler. (Pp 462; $£ 132.50$.$) Raven Press. 1993. ISBN$ 0-7817-0123-6.

This textbook deals in depth with what is a very highly specialised subject, bronchiolar pathology. The editor is an established expert in pulmonary disease and has asked many experts, particularly clinicians, to contribute to the book. The book provides up to the minute information on what is known about bronchiolar disease. It concentrates on infections, smoking, occupational disease, obliterative bronchiolitis, and bronchiolitis organising pneumonia (BOOP), the last two conditions which in the past have been lumped together but which this book clearly separates and clarifies as being different entities with vastly different prognoses. There are excellent chapters on history, anatomy, imaging, pathology, and the various causes of bronchiolar disease. The clinicians' viewpoint is emphasised. However, the penalty of being a multi-author book is that there is discontinuity and a lot of repetition. The editor should have exercised more control over this aspect of the book which makes it very annoying and boring at times when the same references and observations are made by several authors. While not of general interest I would recommend it to pathologists interested in pulmonary pathology as it deals in great depth with what has been pathologically and clinically a very confusing and poorly illustrated area of lung disease in the past.

\section{N SHEPPARD}

\begin{tabular}{|c|}
\hline NoticeS \\
\hline \\
Texas Society of Pathologists \\
75 Years Young \\
presents \\
Pathology: Past, Present and Future \\
Diamond Jubilee Celebration \\
February 1-4 1996 \\
For further information, please contact: \\
Paula Rigling, Texas Society of Path- \\
ologists, 401 West 15th Street, Austin, \\
Texas 78701-1680, USA.
\end{tabular}

Lung pathology course

October 31 to November 31995

National Heart and Lung Institute

For further information, please contact: Professor B Corrin, Histopathology, Royal Brompton Hospital, London SW3 6NP (fax: 01713518435 ).

\begin{tabular}{|c|}
\hline First Announcement \\
5th International Congress on Trace \\
Elements in Medicine and Biology \\
presents \\
Therapeutic Uses of Trace Elements \\
February 4-7 1996 \\
Main topics include: Therapeutic forms \\
of trace elements; large epidemiological \\
and intervention studies related to trace \\
elements; trace element supplementation \\
of population groups of differing ages; and \\
trace elements, bone physiology and bone \\
diseases, among others. \\
For further information, please contact: \\
Madame A Alcaraz, Laboratoire de Bio- \\
chimie C, CHURG, B.P. 217, F-38043 \\
Grenoble Cedex 9, France (tel: (33) 76 \\
7654 84; fax: (33) 76 76 56 64).
\end{tabular}

\section{Postgraduate course \\ Current concepts in surgical pathology \\ November 6-10 1995}

The Department of Pathology, Massachusetts General Hospital, Harvard Medical School, will present a postgraduate course in Surgical Pathology under the direction of Drs Nancy L Harris, Robert H Young and Eugene J Mark.

This course is designed for pathologists at resident and practitioner levels. It will provide an in-depth review of diagnostic surgical pathology with emphasis on morphologic features, newly recognised entities, and new techniques, presented by the faculty of the Department of Pathology, Massachusetts General Hospital. Instruction will be primarily by lecture, but will also include discussion periods. Each participant will receive a comprehensive course syllabus.

The course has Category 1 accreditation for approximately 35 hours CME credit by the American Medical Association. The fee for the course is $\$ 825.00(£ 522.00)$ (residents and fellows $\$ 610.00(£ 386.00)$ ).

For further information, please contact: Department of Continuing Education, Harvard Medical School, 25 Shattuck Street, Boston, MA 02115, USA (tel: (617) 432-1525).

\section{Correction}

Microscopic thymoma and myasthenia gravis (FClin Pathol 1995;48:682-683). The authors apologise for the errors which appeared in the Pathological findings section of their report. In the last line of the first paragraph, $272 \times 71 \mathrm{~mm}$ should read $272 \times 71 \mu \mathrm{m}$. In the final paragraph, $107 \mathrm{~mm}$ (range 41-237 mm) should read $107 \mu \mathrm{m}$ (range 41-237 $\mu \mathrm{m}$ ). 